\title{
The covenantal or communal values of surgeons and intensivists influenced end-of-life care in 3 intensive care units
}

Cassell J, Buchman TG, Streat S, et al. Surgeons, intensivists, and the covenant of care: administrative models and values affecting care at the end of life-Updated. Crit Care Med 2003;31:1551-9.

\section{$Q$ How does end-of-life care differ in intensive care units (ICUs) that use different administrative models?}

\section{DESIGN}

Ethnographic observation.

\section{SETTINGS}

Surgical ICUs in St Louis, Missouri and San Antonio, Texas, and a medical-surgical ICU in Auckland, New Zealand.

\section{PARTICIPANTS}

Approximately 600 physicians, nurses, allied health professionals, patients, family members, and friends.

\section{METHODS}

The first author spent 18 months in the ICU in Missouri; 3 weeks in the ICU in Texas; and 10 weeks in the ICU in New Zealand. Her participation varied by site and included observation of rounds, patient care, and end-of-life discussions with families, as well as interviewing health professionals.

\section{MAIN FINDINGS}

A semi-closed unit with conflicting ethics (Missouri). On this unit, surgeons and intensivists shared responsibility for patient care, but conceptualised this responsibility quite differently. Surgeons appeared to act based on a covenantal ethic, which focused on an individual commitment to battle death on each patient's behalf. In other words, if a patient had a chance to live, it would be morally wrong to deprive that person of that chance. Intensivists, on the other hand, seemed to act based on a communal ethic involving allocation of scarce resources and providing "greatest good to the greatest number." Although concerned with the welfare of all patients in the unit, intensivists were reluctant to continue heroic measures for moribund patients when others who might benefit from services were turned away.

Conflict inevitably occurred between surgeons and intensivists because of their shared responsibility for patients. Disagreements often ensued about shifting patients from "cure" to "comfort" care. It was unclear who had responsibility for final decisions; usually, the physician with the more forceful character and more illustrious reputation prevailed. Intensivists seemed conflicted about extending the ethical concept of autonomy to families' decisions and whether or when to ask families about shifting to comfort care.

Open unit with a covenantal ethic (Texas). In this unit, 5 trauma surgeons made decisions about their own patients. Little conflict existed. The covenantal ethic prevailed, and care was not hastily withdrawn from gravely ill patients. When a surgeon decided a patient had little hope of survival, a resident or intensivist met with the family, who were asked what they wanted to do.

For correspondence: Dr J Cassell, Department of Surgery, Washington University School of Medicine, St Louis, Missouri, USA. casselli@wustl.edu Source of funding: in part, National Institute of Nursing Research.
A closed unit with an ethic of scarcity (New Zealand). The intensivists who staffed this unit used formal strategies to deal with scarcity, including rigorous criteria for admission to the unit and limitation of treatments (based on patient progress and probability of returning to a meaningful quality of life). Decisions were made by consensus, and $>1$ intensivist was always in the ICU to help make decisions. Physicians made end-of-life decisions, which were presented to families as unequivocal medical judgments "not to prolong the dying."

\section{CONCLUSION}

The values implicit in the covenantal or communal ethical stances of surgeons and intensivists in 3 intensive care units influenced end-oflife care and administrative models of those units.

\section{Commentary}

The study by Cassell et al reveals one of the strengths of qualitative research: the context of discovery. Fieldwork is the hallmark of ethnography, and the lead author situated herself in the field for an extended period of time and systematically collected data. Ethnography permitted her to discover, compare, and contrast end-of-life decision making among 3 ICU settings.

Clinical ethnographies ${ }^{1}$ are becoming the norm in healthcare settings. Such ethnographies, while adhering to the tenets of classic ethnography, are more focused or bounded in their purpose. Researchers explore a particular phenomenon of interest, such as how nurses use humour as a therapeutic intervention in a palliative care setting.

The study by Cassell et al has direct implications for nursing practice. The findings reveal that decision making around end-of-life matters in the ICU is fraught with moral and ethical complexities and influenced by many factors. However, beyond administrative models, surgeons and intensivists, cultural and social value sets, and cure versus comfort ethos, was the presence of nurses in all of the ICU settings. Although only tangentially mentioned, nurses were the common thread in Cassell et al's ethnographic tapestry.

Nurses function as brokers and advocates within the clinical milieu through their therapeutic interventions with patients and their families. Data collected by nurses contribute to emergent care and comfort decision making, as well as end-of-life decision making among patients, families, and members of the healthcare team. These are difficult and challenging roles especially in light of the findings of Cassell et al of the multiple forces "at play" in ICU settings, which influence and shape endof-life decision making. Nurses practise within the centre of the cultural, social, ethical/moral, and contextual forces discovered by Cassell et al and must manage these complex forces as they strive for the best patient and family outcomes in ICU settings, including working with families, physicians, surgeons, and intensivists to make end-of-life care decisions.

David Gregory, RN, PhD

University of Manitoba

Winnipeg, Manitoba, Canada

1 Kleinman A. Local worlds of suffering: an interpersonal focus for ethnographies of illness experience. Qual Health Res 1992;2:127-34. 